\title{
Rohu Fish (Labio Rohita) Bile Attenuates Streptozotocin- Induced Diabetes Mellitus in Rats: Evidence from Biochemical and Oxidative Stress Markers
}

\author{
Ahmad D', Pottoo FH $^{2 *}$, Kumar RBS ${ }^{3}$, Haldar $\mathbf{S}^{1}$ \\ and Haldar PK ${ }^{1}$ \\ ${ }^{1}$ Department of Pharmaceutical Technology, J adavpur \\ University, India \\ ${ }^{2}$ Division of Pharmacology, Department of \\ Pharmaceutical Sciences, University of Kashmir, India \\ ${ }^{3}$ University of Montpelier, Place Eugène Bataillon, France \\ *Corresponding author: Faheem Hyder Pottoo, \\ Department of Pharmaceutical Sciences, University of \\ Kashmir, Srinagar, India
}

Received: December 05, 2016; Accepted: January 27, 2017; Published: January 30, 2017

\begin{abstract}
Aim: Present study was undertaken to validate folklore claims regarding antidiabetic activity of the bile of 'Rohu' (Labeo rohita) fish.

Method: Diabetes was induced by single injection of Streptozotocin $(50 \mathrm{mg} /$ $\mathrm{kg})$ in Wistar rats. Diabetic rats were screened and treated with bile (0.08 and $0.16 \mathrm{ml} / \mathrm{kg}$, p.o) daily for 14 days. Fasting blood glucose level was estimated at specific intervals. Serum lipid profiles, serum biochemical parameters related to diabetic pathophysiology and hepatic redox makers were estimated.
\end{abstract}

Result: Oral administration of bile to diabetic rats caused significant and dose dependant hypoglycaemic activity with a maximum reduction of blood glucose level $(\sim 77 \%, p<0.001)$ on day 15 at the dose of $0.16 \mathrm{ml} / \mathrm{kg}$. Bile treatment also could significantly $(p<0.001)$ control hyperlipidemia and restore serum biochemical parameters near to normal values. Diabetic control rats showed a significant $(p<0.001)$ rise in lipid peroxidation and depletion $(p<$ 0.001 ) of antioxidant enzymes in hepatic tissue of diabetic rats as compared with normal rats. Bile treatment, however, could significantly $(p<0.05-0.01)$ revert these changes near to the normal status.

Conclusion: The Labeo rohita fish bile is capable of managing hyperglycaemia, hyperlipidemia and associated complications in diabetes.

Keywords: Anti-hyperglycemic; Anti-hyperlipidemic; Glibenclamide; Diabetes mellitus

\section{Introduction}

Diabetes Mellitus (DM) is a metabolic disorder characterized by elevated blood glucose level due to reduced insulin secretion and/or resistance to insulin action [1]. There are two main forms of diabetes namely type 1 and type 2 . Among them later is more prevalent and account for about $90 \%$ to $95 \%$ of all diagnosed cases of diabetes [2]. According to the hottest postulation, the global population is approaching to the diabetes endemic. Increasing evidence suggests that, oxidative stress plays an important role in the onset and progression of diabetic pathogenesis [3]. The persistent high glucose level in blood leads to generation of reactive oxygen species and consequent oxidative damages in critical organs $[4,5]$. Therefore, it would be worthy to develop novel antidiabetic agent with substantial antioxidant potential to combat against diabetes and associated complications. Despite extensive research on diabetes and its related complications over the last few decades the disease largely remains unabated. Numerous synthetic oral hypoglycemics have been introduced but the situation is only marginally improved. Moreover, side effects of these synthetic molecules largely limit the scope of anti-diabetic therapy. On the other hand, traditional remedies have been serving mankind successfully over hundreds of years to control diabetes and related complications without imparting any undesirable side effects. Traditional medical healers of eastern India claimed that bile content of fresh water fishes could be useful in the management of diabetes. Therefore the present work was undertaken to scientifically evaluate antidiabetic activity the bile content of Labeo rohita (Rohu fish). L. rohita is one of the most popular fresh water fish in India. The bile is known as Bakhwl by the ethnic community of eastern India. It is often consumed by frying with chillies and onion [6]. Bile of L. Rohita consists of bile alcohol, bile acids, sterols, phenolics and traces of steroidal hormones [7]. The present investigation was undertaken to evaluate the effect of Rohu fish bile on hyperglycaemia, hyperlipidemia and oxidative stress in experimental diabetic rats.

\section{Materials and Methods}

\section{Drugs and chemicals}

Streptozotocin (STZ) was obtained from Himedia Pvt. Ltd. India and Glibenclamide (standard drug) from Sanofi India Ltd. Trichloroacetic Acid (TCA) from Merck Ltd., Mumbai, India; Thiobarbituric Acid (TBA), 5,5'- Dithiobis-2-Nitro Benzoic Acid (DTNB), Phenazoniummethosulfate (PMS), Nicotinamide Adenine Dinucleotide (NADH) and Reduced Glutathione (GSH) from Sisco Research Laboratory, Mumbai, India; Potassium dichromate and Glacial acetic acid from Ranbaxy, Mumbai, India; and all the other biochemical reagents kits used were from Span Diagnostics Ltd. India.

\section{Collection of samples}

The fish, L. rohita (1-2 kg), were collected from the local water body at Jadavpur, West Bengal, India. The bile was collected from the 
intact gall bladder of fish. The collected bile was then preserved at $0^{\circ} \mathrm{C}$ for subsequent study.

\section{Animals}

Male wistar rats (2-3 months old) in the weight range of 180-200 g were used for this study. The rats were kept in standard polypropylene cage ( 2 rats/cage). Animals were maintained under standard laboratory conditions of temperature $\left(25 \pm 2{ }^{\circ} \mathrm{C}\right)$, relative humidity $(50 \pm 15 \%), 12 \mathrm{~h}$ light-dark cycle, standard diet and water ad libitum. The principles of Laboratory Animals care [8] and the instructions given by our institutional animal ethical committee were followed throughout the experiment. The animals were allowed to be acclimatized for seven days prior to the experiment.

\section{Acute toxicity study}

Acute toxicity study (upstairs and downstairs method) was performed as previously described $[9,10]$. Sub-toxicity study was done with rat at the oral doses of 0.08 and $0.16 \mathrm{ml} / \mathrm{kg} \mathrm{b.w.} \mathrm{for} 14$ days, and kept for another 14 days post-treatment according to the OECD guidelines [11]. At the end of the 28 days experiment, the animals were sacrificed by cervical dislocation under light ether anesthesia. Before sacrificing the animals, blood samples were collected from retro-orbital venous plexus in eppendrof tubes rinsed with anticoagulant for hematological assays. The serum biochemical analysis was performed by standard enzymatic assay methods.

\section{Oral glucose tolerance test (OGTT)}

OGTT was performed in $16 \mathrm{~h}$ fasted rats. Rats were divided into three groups $(n=6)$. Group I serve as normal control and received distilled water ( $5 \mathrm{ml} / \mathrm{kg}$ b.w., p.o.), and groups II and III received bile at doses of 0.08 and $0.16 \mathrm{ml} / \mathrm{kg}$ b.w., p.o., respectively. After these treatments, all groups received glucose ( $2 \mathrm{~g} / \mathrm{kg}$ b.w., p.o.) orally. Blood was withdrawn from the tail vein just prior to and 30, 60, 120 and 240 min after oral glucose administration [12]. Blood glucose levels in tail blood were measured using a one touch glucometer (Contour TS, Bayer Healthcare, USA).

\section{Induction of diabetes and treatment schedule}

Diabetes was induced by single dose $(50 \mathrm{mg} / \mathrm{kg}$ b.w., i.p.) of STZ solution prepared in cold citrate buffer $(0.1 \mathrm{M}, \mathrm{pH} 4.5)$. After 72 hours, Fasting Blood Glucose (FBG) level was measured. The animals exhibiting FBG level $>250 \mathrm{mg} / \mathrm{dl}$ were screened for this study [13]. The rats were divided into five groups $(\mathrm{n}=6)$ as follows:

Group I: Normal rats administered double distilled water $(5.0 \mathrm{ml} /$ $\mathrm{kg}$ p.o.) daily for 14 days.

Group II: Diabetic rats administered distilled water $(5.0 \mathrm{ml} / \mathrm{kg}$ p.o.) daily for 14 days.

Group III: Diabetic rats administered bile $(0.08 \mathrm{ml} / \mathrm{kg}$ b.w. p.o. $)$ daily for14 days.

Group IV: Diabetic rats administered bile $(0.16 \mathrm{ml} / \mathrm{kg}$ b.w. p.o. $)$ daily for14 days.

Group V: Diabetic rats administered standard drug glibenclamide ( $0.5 \mathrm{mg} / \mathrm{kg}$ p.o.) daily for 14 days.

\section{Biochemical analysis}

FGB level was estimated on day $0,1,5,10,15$ with the help of single touch glucometer (Contour TS, Bayer Healthcare, USA). On day 15, all the rats were anaesthetized and sacrificed by cervical dislocation. Before sacrificing the animals, blood samples were collected from retro-orbital venous plexus in eppendroff tubes rinsed with anticoagulant for the estimation of serum biochemical parameters. Livers were excised, washed and homogenized in $0.1 \mathrm{M}$ Tris- $\mathrm{HCl}$ buffer ( $\mathrm{pH}$ 7.4). This tissue homogenate was used for the estimation of antioxidant markers. From the collected blood, serum was separated that was used for the estimation of serum biochemical parameters like Total Cholesterol (TC), Triglyceride (TG), High Density Lipoprotein (HDL), Serum Glutamic Oxaloacetic Transaminase (SGOT), Serum Glutamic Pyruvic Transaminase (SGPT) and Serum Alkaline Phosphatase (SALP). All tests were performed by using commercially available Span Diagnostic kits.

Lipid Peroxidation (LPO) was assayed according to the method of Ohkawa et al. [14]. Superoxide Dismutase (SOD) activity was assayed according to the method of Murklund and Murklund [15]. SOD activity was expressed as Units $/ \mathrm{mg}$ protein $/ \mathrm{min}$. Catalase activity was measured and expressed as moles of $\mathrm{H}_{2} \mathrm{O}_{2}$ decomposed $/ \mathrm{min} / \mathrm{mg}$ of tissue [16]. Non-enzymatic antioxidant, reduced Glutathione (GSH), was determined by the method of Ellman [17].

\section{Statistical analysis}

All the data was statistically evaluated by one-way Analysis of Variance (ANOVA) followed by post hoc Dunnett's test with Graph Pad Prism 5 software. All the results were expressed as Mean \pm SEM for six animals in each group; $p$ values of less than 0.05 were considered to indicate statistical significance.

\section{Results}

\section{Acute toxicity}

LD50 of the bile was found to be $1.6 \mathrm{ml} / \mathrm{kg}$ b.w., p.o. In subacute toxicity study, the rats received repeated oral doses of bile at 0.08 and $0.16 \mathrm{~g} / \mathrm{kg}$ b.w. for 14 days. No sign of toxicity was observed in their physiological and behavioural pattern during the 14 days observation period. No signs of toxicity and mortality were observed in the treated group as compared to the control group. No significant alteration was observed in body weight. Beside this, serum biochemical parameters remained almost similar to that of control animals (data not shown). Therefore, the results obtained suggest that bile is fairly nontoxic at the selected doses.

\section{Oral glucose tolerance test (OGTT)}

The OGTT showed dose dependent anti-hyperglycaemic effect of bile $(0.08$ and $0.16 \mathrm{ml} / \mathrm{kg})$ in rats $(\mathrm{p}<0.01, \mathrm{p}<0.001)$ at $60 \mathrm{~min}$, while at 30 and 120 minute intervals the significant $(\mathrm{p}<0.01)$ antihyperglycaemic effect was only evident with higher dose of bile $(0.16$ $\mathrm{ml} / \mathrm{kg}$ ).

\section{Effect of bile on hyperglycaemia}

The bile at the doses of 0.08 and $0.16 \mathrm{ml} / \mathrm{kg}$ b.w. significantly lowered FBG level in diabetic rats and exhibited maximum reduction of $27 \%(\mathrm{p}<0.01)$ and $33 \%(\mathrm{p}<0.01)$ on day 15 , with respect to initial blood glucose concentration of respective groups. The results were comparable with standard oral hypoglycaemic agent glibenclamide $(0.5 \mathrm{mg} / \mathrm{kg}$ b.w.) which exhibited maximum reduction of $45 \%$ ( $\mathrm{p}<$ 0.01 ) on day 15 (Figure 1). 


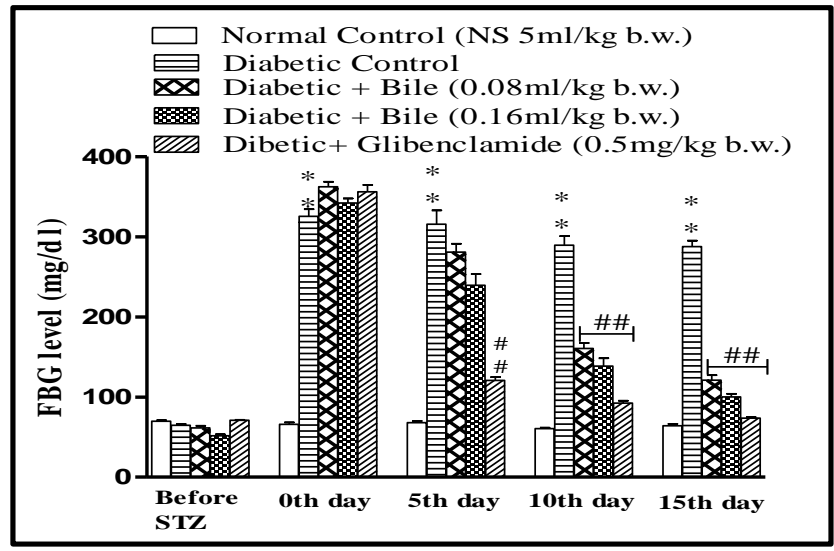

Figure 1: Effect of fish bile on Fasting Blood Glucose (FBG) level in STZ induced diabetic rats. All drugs were administered for 14 days post STZ $(50 \mathrm{mg} / \mathrm{kg}$, i.p) induced diabetes in rats. Data is represented as Mean \pm SEM of 6 animals per group, $" \mathrm{p}<0.05,{ }^{\#} \mathrm{p}<0.01, \# \mathrm{n} p<0.001$ (compared to normal control). $" \mathrm{p}<0.05,{ }^{\#} \mathrm{p}<0.01, \ldots \mathrm{p}<0.001$ (compared to diabetic control) Significant by one way ANOVA followed by Dunnett's test.

\section{Serum biochemical parameters}

After 14 days of treatment with bile $(0.08$ and $0.16 \mathrm{ml} / \mathrm{kg} \mathrm{b.w})$ it was found that the Total Cholesterol (TC) and Triglyceride (TG) levels were significantly $(\mathrm{p}<0.001)$ restored towards normal with both doses of bile. The said effects were almost similar to glibenclamide $(0.5 \mathrm{mg} / \mathrm{kg}$ b.w). However bile ( 0.08 and $0.16 \mathrm{ml} / \mathrm{kg}$ b.w) failed to exhibit significant protection against depleted HDL levels in diabetic rats (Table 1).

The increase in SGOT, SGPT and SALP levels in STZ induced diabetic rats also substantiated the hepatic damage by STZ. Treatment with bile $(0.08$ and $0.16 \mathrm{ml} / \mathrm{kg} \mathrm{b.w})$ significantly $(\mathrm{p}<0.05, \mathrm{p}<0.01)$, $(\mathrm{p}<0.05, \mathrm{p}<0.01)$ and $(\mathrm{p}<0.01, \mathrm{p}<0.001)$ restored all the above mentioned hepatic biochemical parameters in a dose dependent manner. The highest protective effect was observed with bile $(0.16$ $\mathrm{ml} / \mathrm{kg}$ ) on SALP levels, an effect comparable with glibenclamide, a standard anti-diabetic drug was recorded. The hepatic damage was reduced in bile treated diabetic rats as compared to the STZ control rats (Figure 2).

\section{Liver biochemical parameters and antioxidant status}

Endogenous enzymatic antioxidant (CAT, SOD) and nonenzymatic antioxidant (GSH) act as reducing agents and detoxify highly reactive oxygen and nitrogen species. Induction of diabetes in

Table 1: Effect of fish bile on serum lipid profiles.

\begin{tabular}{|c|c|c|c|}
\hline Groups & $\begin{array}{l}\text { Triglyceride } \\
\text { (mg/dl) }\end{array}$ & $\begin{array}{c}\text { Total cholesterol } \\
\text { (mg/dl) }\end{array}$ & $\begin{array}{c}\text { HDL } \\
(\mathrm{mg} / \mathrm{dl})\end{array}$ \\
\hline Normal control & $82.70 \pm 1.52$ & $49.25 \pm 1.69$ & $69.95 \pm 2.56$ \\
\hline Diabetic control & $154.4 \pm 1.19^{* * *}$ & $105.9 \pm 2.33^{* * *}$ & $31.93 \pm 3.44^{* * *}$ \\
\hline $\mathrm{STZ}+$ Bile $(0.08 \mathrm{ml} / \mathrm{kg})$ & $106.7 \pm 2.97^{\# \# \#}$ & $69.01 \pm 2.10^{\# \# \#}$ & $35.58 \pm 1.89$ \\
\hline STZ+ Bile $(0.16 \mathrm{ml} / \mathrm{kg})$ & $100.3 \pm 2.03^{\# \# \#}$ & $65.25 \pm 1.49^{\# \# \#}$ & $39.14 \pm 2.72$ \\
\hline $\begin{array}{c}\text { Diabetic + Glibenclamide } \\
(0.5 \mathrm{mg} / \mathrm{kg})\end{array}$ & $97.97 \pm 3.21^{\# \# \# ~}$ & $56.19 \pm 2.19^{\# \# \#}$ & $57.75 \pm 2.11^{\# \# \# ~}$ \\
\hline \multicolumn{4}{|c|}{ 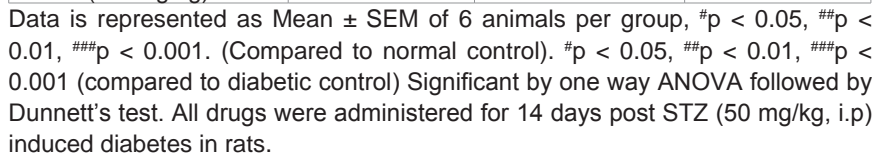 } \\
\hline
\end{tabular}
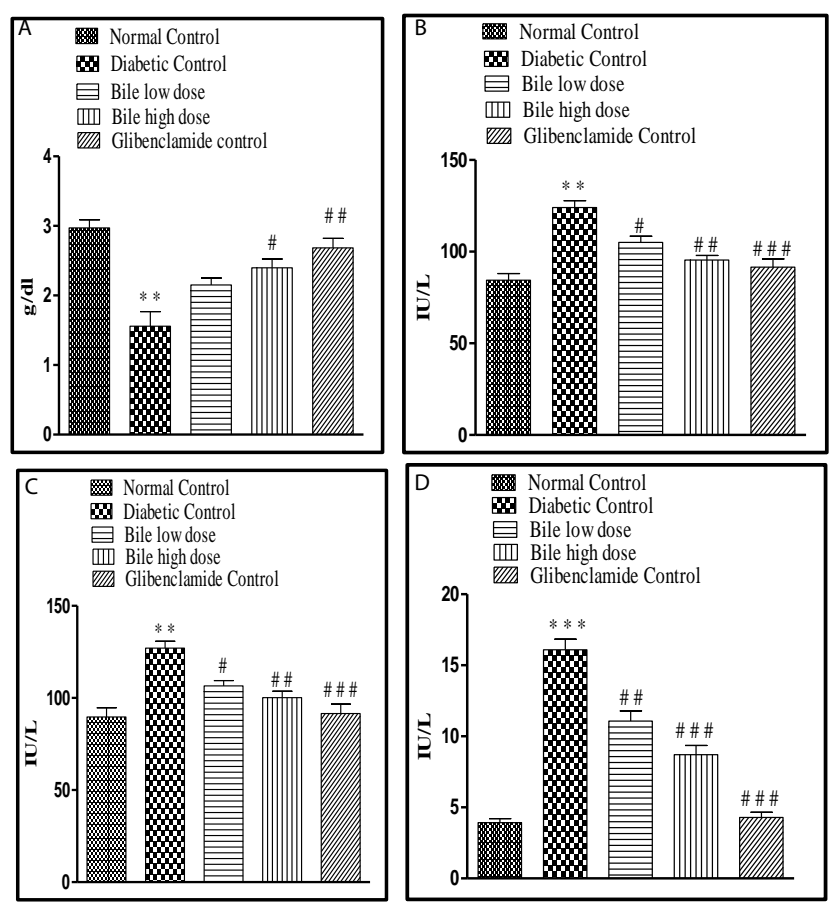

Figure 2: Effect of fish bile on serum biochemical parameters; total protein count (a), SGOT (b), SGPT (c) and SALP (d) in STZ induced diabetic rats. All drugs were administered for 14 days post STZ $(50 \mathrm{mg} / \mathrm{kg}$, i.p) induced diabetes in rats. Data is represented as Mean \pm SEM of 6 animals per group, $\# p<0.05, \# p<0.01, \# p<0.001$ (compared to normal control). $\# p<0.05$ $\#$ p $<0.01, \#$ p $<0.001$ (compared to diabetic control) Significant by one way ANOVA followed by Dunnett's test.

rats culminated in significant $(\mathrm{p}<0.001)$ rise in MDA levels. GSH, SOD and Catalase exhibited a significant $(\mathrm{p}<0.001)$ fall in levels compared to levels in normal rats.

Treatment with bile $(0.08$ and $0.16 \mathrm{ml} / \mathrm{kg} \mathrm{b.w)}$ significantly $(\mathrm{p}<$ 0.001) restored MDA levels. The effect obtained at both dose levels was almost similar and comparable to glibenclamide. Significant $(\mathrm{p}<0.05, \mathrm{p}<0.01)$ and dose dependent increase in GSH levels was obtained on treatment with bile $(0.08$ and $0.16 \mathrm{ml} / \mathrm{kg} \mathrm{b.w})$. However lower dose of bile $(0.08 \mathrm{ml} / \mathrm{kg})$ exhibited insignificant elevation in SOD and CAT levels, with significant $(\mathrm{p}<0.05)$ elevation only at higher dose of bile $(0.16 \mathrm{ml} / \mathrm{kg})$ (Table 2$)$.

\section{Discussion}

It was observed that bile significantly decreased FBG level in rats. The possible mechanism by which bile brings about its antihyperglycaemic activity may be by increasing the pancreatic secretion of insulin from the existing beta cells or facilitating its release from the bound insulin [18].

Hyperglycaemia increase the generation of free radicals by glucose auto-oxidation and depletes the activity of antioxidant defence system hence de novo free radicals generation leads to liver cell damage [19]. A marked increase of LPO in STZ treated rats leading to tissue injury and failure of the endogenous antioxidant defence mechanisms to prevent over production of free radicals was observed.

There was an increase in the Triglyceride (TG), cholesterol and 
Table 2: Effect of fish bile on liver biochemical parameters. Lipid peroxidation (mM of MDA/mg of tissue), GSH ( $\mu \mathrm{g} / \mathrm{mg}$ of tissue), SOD (U/mg of tissue) and Catalase (mM of $\mathrm{H}_{2} \mathrm{O}_{2}$ consumed/min/mg of tissue).

\begin{tabular}{|c|c|c|c|}
\hline Groups & MDA & GSH & SOD \\
\hline Normal control & $107.9 \pm 1.74$ & $3.93 \pm 0.12$ & $15.70 \pm 0.78$ \\
\hline Diabetic control & $173.2 \pm 3.16^{* * *}$ & $1.38 \pm 0.09^{* * *}$ & $3.36 \pm 0.25^{* * *}$ \\
\hline STZ + bile $(0.08 \mathrm{ml} / \mathrm{kg})$ & $145.1 \pm 1.94^{\# \# \#}$ & $2.03 \pm 0.12^{\#}$ & $5.38 \pm 0.87$ \\
\hline STZ+ bile $(0.16 \mathrm{ml} / \mathrm{kg})$ & $123.0 \pm 2.91^{\# \# \#}$ & $2.21 \pm 0.11^{\# \#}$ & $7.89 \pm 0.92^{\#}$ \\
\hline $\begin{array}{c}\text { Diabetic }+ \text { glibenclamide } \\
(0.5 \mathrm{mg} / \mathrm{kg})\end{array}$ & $111.1 \pm 1.64^{\# \# \#}$ & $2.73 \pm 0.12^{\# \# \#}$ & $2.02 \pm 0.11^{\#}$ \\
\hline
\end{tabular}

Data is represented as Mean \pm SEM of 6 animals per group, $\# p<0.05$, \#\#p $<0.01$, \#\#p $<0.001$ (compared to normal control). \#p $<0.05$, \#\#p $<0.01$, \#\#p $<0.001$ (compared to diabetic control) Significant by one way ANOVA followed by Dunnett's test. All drugs were administered for 14 days post STZ (50 mg/kg, i.p) induced diabetes in rats.

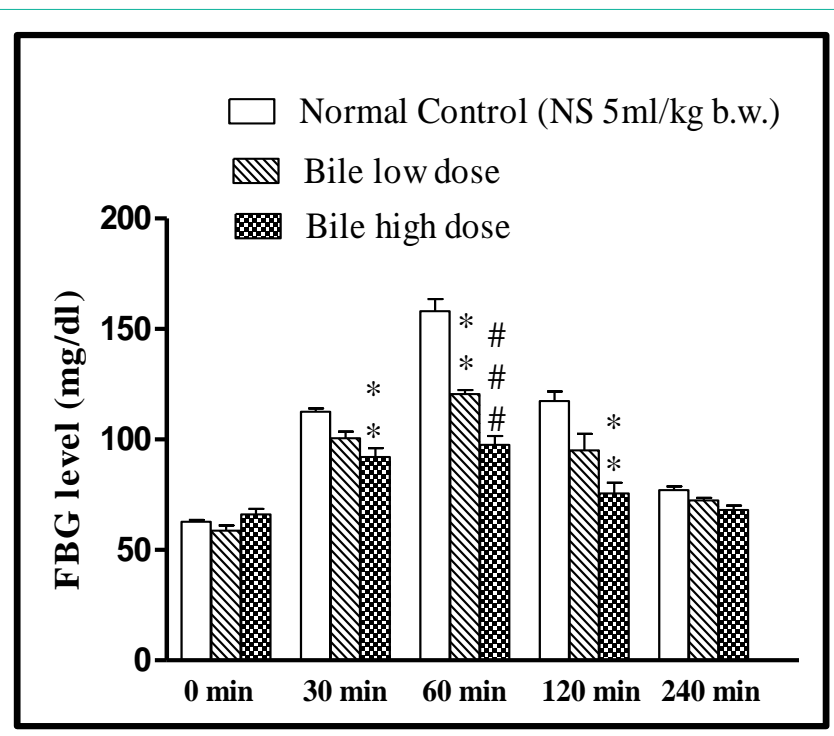

Figure 3: Effect of fish bile on oral glucose tolerance test (OGTT). Data is represented as Mean \pm SEM of 6 animals per group, $\# p<0.05, \# p<0.01$, $\#$ p $<0.001$ (compared to normal control). $" p<0.05, \# p<0.01, \# p<0.001$ (compared to diabetic control). Significant by one way ANOVA followed by Dunnett's test.

decrease in the HDL levels in the diabetic rats. This might have occurred in the diabetic rats as a result of lack of insulin which activates the lipase enzymes. Lipase enzyme in turn hydrolyzes the stored TG and releases large amounts of fatty acids and glycerol in the circulating blood. Consequently, the excess of fatty acids in the plasma may promote the hepatic conversion of fatty acids into phospholipids and cholesterol, the main product of lipid metabolism [20]. The increase level of TG and cholesterol in the blood of diabetic rats leads to cardiovascular complications. The improvements in the lipid profile of diabetic animals after treatment with bile could be beneficial in preventing diabetic complications as well as improving lipid metabolism [21]. Elevation of serum biomarker enzymes such as SGOT, SGPT and SALP were observed in diabetic rats indicating impaired liver function, which is obviously due to hepatocellular necrosis. Diabetic complications such as increased gluconeogenesis and ketogenesis may be due to elevated transaminase activities [22]. Restoration of these biomarker enzymes towards normal level indicates decreased diabetic complications in bile treated groups.

Enzymatic antioxidant mechanisms play an important role in the elimination of free radicals. Catalase is a haem containing enzyme catalyzing detoxification of $\mathrm{H} 2 \mathrm{O} 2$ to water and oxygen
[23]. The inhibition of catalase activity as the result of STZ-induced hyperglycaemia was reported earlier [24] and similar findings were observed in the present study. LPO is usually measured in terms of TBARS as a biomarker of oxidative stress [25]. The reduction in liver antioxidant status during diabetes may be the result of counteraction against increased formation of lipid peroxides [26]. A marked increase in the concentration of TBARS in STZ induced diabetic rats indicated enhanced lipid peroxidation leading to tissue injury and failure of the endogenous antioxidant defense mechanisms to prevent over production of free radicals. Treatment with bile inhibited hepatic LPO and restored liver antioxidant parameters towards normal levels that improved the pathologic complications of diabetes due to less tissue injury [27].

\section{Conclusion}

Thus the present study indicated that the treatment with bile has favourable effect not only on blood glucose levels but also on serum lipids and biochemical parameters. These findings point out the promising effect of fish (Labeo rohita) bile as a useful antidiabetic agent.

\section{Acknowledgements}

The authors are grateful to the authority of Jadavpur University, Kolkata, India, for providing research facilities and technical support. They are also thankful to All India council for Technical Education (AICTE) and UGC New Delhi, India for financial support.

\section{References}

1. Dewanjee S, Das AK, Sahu R, Gangopadhyay M. Antidiabetic activity of Diospyros peregrina fruit: Effect on hyperglycemia, hyperlipidemia and augmented oxidative stress in experimental type 2 diabetes. Food Chem Toxicol. 2009; 47: 2679-2685.

2. Dewanjee S, Maiti A, Das AK, Mandal SC, Dey SP. Swietenine: A potentia oral hypoglycemic from Swietenia macrophylla seed. Fitoterapia. 2009; 80: 249-251.

3. Koya D, King GL. Protein kinase C activation and the development of diabetic complications. Diabetes. 1998; 47: 859-866.

4. Kakkar R, Mantha SV, Radhi J, Prasad K, Kalra J. Increased oxidative stress in rat liver and pancreas during progression of streptozotocin induced diabetes. Clin Sci. 1998; 94: 623-632.

5. Mohamed AK, Bierhaus A, Schiekofer S. The role of oxidative stress and NF (B) activation in late diabetic complications. Biofactors. 1999; 10: 175-179.

6. De B, Deb SR, Chakraborty S, Namasudra U, Pal MR, Choudhury R, et al. Antibacterial and antidiabetic evaluation of bile content of Catla catla \& Labeo rohita. Central Eur J Exp Biol. 2012; 1: 107-112.

7. Hofmann AF, Hagey LR, Kraswski MD. Bile salts of vertebrate: structural 
variation and possible evolutionary significance. J Lipid Res. 2010; 51: 226246 .

8. PHS (Public Health Service). Public Health Service Policy on Humane Care and Use of Laboratory Animals. Washington, DC, US, Department of Health and Human Services. 1986

9. The Organisation of Economic Co-operation and Development (OECD). The OECD Guideline for Testing of Chemical: 407 Repeated Dose Oral ToxicityRodent: 28-day or 14-day Study. OECD, Paris. 2001; 1-7.

10. Dewanjee S, Dua TK, Sahu R. Potential anti-inflammatory effect of Leea macrophylla Roxb. leaves: A wild edible plant. Food Chem Toxico.2013; 59: 514-520

11. The Organisation of Economic Co-operation and Development (OECD). The OECD Guideline for Testing of Chemical: 420 Acute Oral Toxicity. OECD, Paris. 2001; 1-14.

12. Haldar PK, Kar B, Bhattacharya S, Bala A, Kumar RBS. Antidiabetic activity and modulation of antioxidant status by sansevieria roxburghiana rhizome in streptozotocin-induced diabetic rats. Diabetologia Croatica. 2010; 39: 115123.

13. Naskar S, Mazumder UK, Pramanik G, Gupta M, Kumar RBS, Bala A, et al. Evaluation of antihyperglycemic activity of Cocos nucifera Linn.on streptozotocin induced type 2 diabetic rats. Journal of Ethnopharmacology. 2011; 138: 769-773.

14. Ohkawa H, Ohishi N, Yagi K. Assay for lipid peroxides in animal tissues by thiobarbituric acid reaction. Anal Biochem. 1979; 95: 351-358.

15. Murklund S, Murklund, G. Involvement of the superoxide anion radical in the antioxidation of pyrogallol and a convenient assay for superoxide dismutase. Eur J Biochem. 1974; 47: 469-474.

16. Sinha KA. Colorimetric assay of catalase. Annal Biochem. 1972; 47: 389-394

17. Ellman GL. Tissue sulfhydryl groups. Arch Biochem Biophys. 1959; 82: 70 77.
18. Mana S, Singhal S, Sharma NK, Singh D. Hypoglycemic effect of Holarrhena antidysenterica seeds on streptozotocin induced diabetic rats. Int J Pharm Tech Res. 2010; 2: 1325-1329.

19. Baynes JW, Thorpe SR. The role of oxidative stress in diabetic complications. Curr Opin Endocrinol Diabetes Obes. 1997; 3: 277-284.

20. Swanston-Flat SK, Day C, Bailey CJ, Flatt PR. Traditional plant treatments for diabetes: studies in normal and streptozotocin diabetic mice. Diabetologia. 1990; 33: 462-464.

21. Cho SY, Park JY, Park EM, Choi MS, Lee MK, Jeon SM, et al. Alteration of hepatic antioxidant enzyme activities and lipid profile in streptozotocin induced diabetic rats by supplementation of dandelion water extract. Clinica Chemica Acta. 2002; 317: 109-117.

22. Ghosh S, Suryawansi SA. Effect of Vinca rosea extracts in treatment of alloxan diabetes in male albino rats. Indian J Exp Biol. 2001; 39: 748-759.

23. Gokce G, Haznedaroglu MZ. Evaluation of antidiabetic, antioxidant and vasoprotective effects of Posidonia oceania extract. J Ethnopharmacol. 2008; 115: $122-130$.

24. Janero DR. Malondialdehyde and thiobarbituric acid reactivity as diagnostic indices of lipid peroxidation and peroxidative tissue injury. Free Rad Biol Med. 1990; 9: 515-540.

25. Venukumar MR, Latha MS. Antioxidant activity of Curculigo orchioides in carbon tetrachloride induced hepatopathy in rats. Indian J Clin Biochem. 2002; 17: 80-87.

26. Sabu MC, Kuttan R. Antidiabetic activity of Aegle marmelos and its relationship with its antioxidant properties. Indian J Physiol Pharmacol. 2004; 48: 81-88.

27. International diabetes federation. IDF Diabetes Atlas. 2013.
Austin J Pharmacol Ther - Volume 5 Issue 1 - 2017 ISSN: 2373-6208 | www.austinpublishinggroup.com Pottoo et al. (@) All rights are reserved
Citation: Ahmad D, Pottoo FH, Kumar RBS, Haldar S and Haldar PK. Rohu Fish (Labio Rohita) Bile Attenuates Streptozotocin-Induced Diabetes Mellitus in Rats: Evidence from Biochemical and Oxidative Stress Markers. Austin J Pharmacol Ther. 2017; 5(1).1087. 